Research Article

\title{
Study on Reasonable Size of Coal and Rock Pillar in Dynamic Pressure Roadway Segment of Fully Mechanized Face in Deep Shaft
}

\author{
Binyang Sun $\mathbb{D}^{1},{ }^{1,2}$ Pingsong Zhang $\mathbb{D}^{1},{ }^{1,2}$ and Haifeng Lu $\mathbb{i D}^{2}$ \\ ${ }^{1}$ State Key Laboratory of Mining Response and Disaster Prevention and Control in Deep Coal Mines, \\ Anhui University of Science and Technology, Huainan, Anhui 232001, China \\ ${ }^{2}$ Department of Earth and Environment, Anhui University of Science and Technology, Huainan, Anhui 232001, China
}

Correspondence should be addressed to Pingsong Zhang; pszhang1971@163.com

Received 18 August 2020; Revised 23 September 2020; Accepted 28 September 2020; Published 10 October 2020

Academic Editor: Zhijie Wen

Copyright (c) 2020 Binyang Sun et al. This is an open access article distributed under the Creative Commons Attribution License, which permits unrestricted use, distribution, and reproduction in any medium, provided the original work is properly cited.

The deformation mechanism of the protective coal and rock pillar area outside a stope is an important parameter for setting a reasonable size. In this paper, based on the geological condition of working face 1231(1) in a mine in Huainan, a method that combines the use of a borehole and Brillouin optical time domain reflectometry (BOTDR) was proposed to analyze the stress variation laws of coal and rock pillar areas, and the parameters of the monitoring borehole and installation technique of the sensing optical cables were designed. Based on the monitoring data, the strain distribution characteristics of the sensing optical cables and their relationship with the rock strata were analyzed, the development law of coal and rock strata deformation during the mining process was revealed, and the transverse influence range of the coal and rock pillar affected by mining was reasonably divided. According to the results, the sensing optical cables show an overall trend of tensile strain, with a maximum value of $1800 \mu \varepsilon$, and the main areas of rock strata deformation occur near the interface of rock strata. The range of rock strata disturbance along the borehole direction was approximately $38 \mathrm{~m}$, and the maximum deformation of rock strata after the disturbance, namely, the displacement, was $24.87 \mathrm{~mm}$. A numerical model was constructed to acquire the strain variation characteristic within $100 \mathrm{~m}$ in the outer floor of the working face. The transverse range of the floor disturbance was analyzed to be $30-36 \mathrm{~m}$. The field test had good correspondence with the numerical simulation results, which indicates that the optical fiber testing technology can effectively describe the stress variation in the coal and rock strata. The test results can provide technical support for the rational setting of coal and rock pillars and disaster prevention and control. The research direction of deep rock mass testing is discussed, and optical fiber testing in boreholes is considered an effective method for studying deep dynamic disaster control.

\section{Introduction}

In the process of mining and utilizing deep coal resources, with the increase in mining depth, the mechanical properties of the roadway surrounding rock tend to become more complicated, and the degree of roadway deformation continuously increases because of the mining effects. A reasonable and effective roadway layout and protective coal and rock pillars of a certain size are important factors in roadway deformation problems. Many factors affect the preservation and setting of protective coal and rock pillars, such as the overburden lithology, underlying aquifer, strength of coal and rock masses, mining depth and thickness, and coal seam dip angle [1]. Many scholars have studied the setting of protective coal and rock pillars, but there is no uniform and effective method to determine parameters such as the setting size. In the early stage, mainly based on the travelling angle, the section method, vertical line method, digital elevation projection method, empirical analogy, and formula calculation were used, but mostly in shallow coal seam mining [2-4]. Compared with the traditional methods, numerical simulation can consider many complicated factors. Lu et al. proposed the establishment of a two-dimensional finite element model based on ANSYS and performed numerical 
simulations for protective coal and rock pillars in the presence of faults [5]. Wei et al. established a mathematical model with MATLAB to automate the protective coal and rock pillar design [6]. Zhang et al. used FLAC ${ }^{3 \mathrm{D}}$ to analyze the mechanical properties of roadways surrounding rock under mining conditions and performed studies on reasonably setting protective coal pillars [7]. However, the numerical simulation process is mostly based on the idealized state implementation parameters, and it is necessary to analyze on the adaptability of the obtained results for a deep and complex geomechanical environment. In the process of deep coal seam mining, the mechanical properties of the surrounding rock become more complicated because of the influence of "three high and one disturbance." Therefore, it is very important to master the deformation characteristics of the coal and rock strata in the surrounding rock space during the mining process. The field test technique can be used to test the stress state and spatiotemporal evolution of coal and rock masses, and the continuous data obtained by this method have direct significance for the setting of coal and rock pillars. However, current research on such applications is rare.

In the initial stage, distributed fiber optic sensing (DFOS) technology is mainly applied to engineering structures such as bridges, tunnels, and foundation pits [8-13]. However, in recent years, DFOS technology has been gradually introduced into mine production. Zhang et al. dynamically monitored the deformation and failure of overburden based on DFOS technology and noted that DFOS was an effective method for strata strain monitoring in the similarity model and field test of coal mining $[14,15]$. Chai et al. developed a plane geological model and detected the deformation and collapse processes of rock strata with distributed optical fibers using Brillouin optical time domain analysis (BOTDA) [16]. Sun et al. used BOTDR to dynamically monitor the failure characteristic of overburden strata in coal seam mining and accurately determined the fractured zone with borehole resistivity CT [17]. Hu et al. [18] and Tang and Cheng [19] used BOTDR to monitor the coal mine surrounding rock deformation and provided technical solutions to optimize the mining design. Based on the vertical borehole on the ground, BOTDR was used to monitor the deformation and failure of the overburden of the stope. Compared with the traditional monitoring methods, BOTDR monitoring provided more accurate data on the dynamic height of the fractured zone. The research results are helpful in preventing or mitigating water inrush and surface ecological geological disasters [20,21].

In this paper, the spatiotemporal evolution of the stress state of the outer coal and rock strata under mining conditions was monitored and analyzed based on DFOS technology and the coal and rock strata conditions of the protective coal pillar sections of the working face 1231(1) in a mine in Huainan. Using the FLAC ${ }^{3 \mathrm{D}}$ numerical simulation software, the stress characteristic of the surrounding rock was comprehensively analyzed, and the stress influence range in the mining face was delineated, which provides a method and technical reference for setting protective coal and rock pillars under similar geological conditions.

\section{Design of the Field Test Scheme}

2.1. Geological Conditions. The working face 1231(1) mainly mines coal seam 11-2; the floor elevation is from -839.1 to $778.3 \mathrm{~m}$, the length in the strike direction is $1366 \mathrm{~m}$, and the inclined length is $240 \mathrm{~m}$. The coal seam storage is stable, with a thickness of $0.2-8.0 \mathrm{~m}$ and an average thickness of $2.45 \mathrm{~m}$. The occurrence of the coal seam is at between $60^{\circ}$ and $175^{\circ}$, with a dip angle of $0-10^{\circ}$ and an average dip angle of $4^{\circ}$. There is a ventilation roadway and a haulage roadway in the working face, and the outer side of the ventilation roadway is the protective coal and rock pillar section of the previous working face. The lithological distribution of the roof and floor is shown in Table 1.

2.2. Test System Layout. The test system was arranged in the ventilation roadway, and sensing cables were implanted into the coal and rock mass via drilling installation. The borehole was perpendicular to the ventilation roadway of the working face and pointed to the outer coal and rock pillar. The borehole was designed to be constructed along the incline of the coal seam. Restricted by construction conditions, the inclination angle of the borehole was $-6^{\circ}$, and the azimuth angle was $7^{\circ}$ when it was formed. After the PVC tube was tightly coupled with the optical cables, they were artificially sent to the bottom of the borehole. The length of the optical cables was $101.5 \mathrm{~m}$. The horizontal control distance of the coal and rock strata outside the roadway was $100.9 \mathrm{~m}$. The installation layout of the test system is shown in Figure 1.

To fully couple the optical cables with the surrounding rock, the optical cables were attached to the outer wall of the PVC tube and embedded in the surrounding rock by drilling. First, the optical cables were bonded to the outer wall of the PVC tube by a fixed component. To ensure that the optical cables were not twisted, the fixed spacing was set as $1.5 \mathrm{~m}$. Second, the length of the PVC implanted tube was prolonged by a serial connection device. The optical cables were fixed according to this method, and the optical cables were embedded to the targeted borehole depth. Finally, the orifice was closed via full-borehole grouting. During borehole grouting, the grouting should be divided into sections from the inside to the outside, and the corresponding material in terms of strength should be injected to ensure the grouting solidification strength and effective coupling between the optical cables and the surrounding rock to obtain the stress field variation characteristics of cooperative deformation $[22,23]$. During grouting, there was a pressurized grouting device in the drilling borehole, and the entire injection process ended when the slurry was returned to the borehole. In mining, when the coal and rock strata are deformed or destroyed, elongation deformation is produced in the optical cable. Using Formulas (2) and (3) to calculate the deformation of the optical cables, we can deduce the variation in the surrounding rock and provide a basis for the study of the stress distribution law in the surrounding rock. 
TABLE 1: The lithological distribution of the roof and floor of coal seam 11-2.

\begin{tabular}{|c|c|c|c|}
\hline Roof or floor & Lithology & Thickness (m) & Lithological description \\
\hline Main roof & Fine sandstone & $\begin{array}{c}0-10.25 \\
0.6\end{array}$ & $\begin{array}{c}\text { Light gray, fine grained, main mineral is quartz, and rock is dense and } \\
\text { hard }\end{array}$ \\
\hline $\begin{array}{l}\text { Immediate } \\
\text { roof }\end{array}$ & $\begin{array}{l}\text { Sandy mudstone and } \\
\text { carbonaceous mudstone }\end{array}$ & $\begin{array}{l}0-20.45 \\
5.2\end{array}$ & $\begin{array}{l}\text { Gray, sandy muddy structure, rich in plant stem and leaf fossils, and } \\
\text { brittle rock. An unstable carbonaceous mudstone is locally developed. }\end{array}$ \\
\hline $\begin{array}{l}\text { Immediate } \\
\text { floor }\end{array}$ & $\begin{array}{l}\text { Mudstone, sandy mudstone, and } \\
\text { carbonaceous mudstone }\end{array}$ & $\begin{array}{c}1.4-16.35 \\
9.5\end{array}$ & $\begin{array}{l}\text { Mainly gray to dark gray and sandy muddy structure. Carbonaceous } \\
\text { composition and silty sandstone interlayer are locally developed. Rock } \\
\text { is brittle and fragile. }\end{array}$ \\
\hline Main floor & Fine sandstone & $\begin{array}{c}2.3-14.7 \\
11.8\end{array}$ & $\begin{array}{l}\text { Light gray to gray white, fine-grained structure, and main mineral is } \\
\text { composition quartz. Sandy mudstone interlayer is locally developed. } \\
\text { Rock is dense and hard. }\end{array}$ \\
\hline
\end{tabular}

Note: $0-10.25$ is the thickness range, and 0.6 is the average thickness.

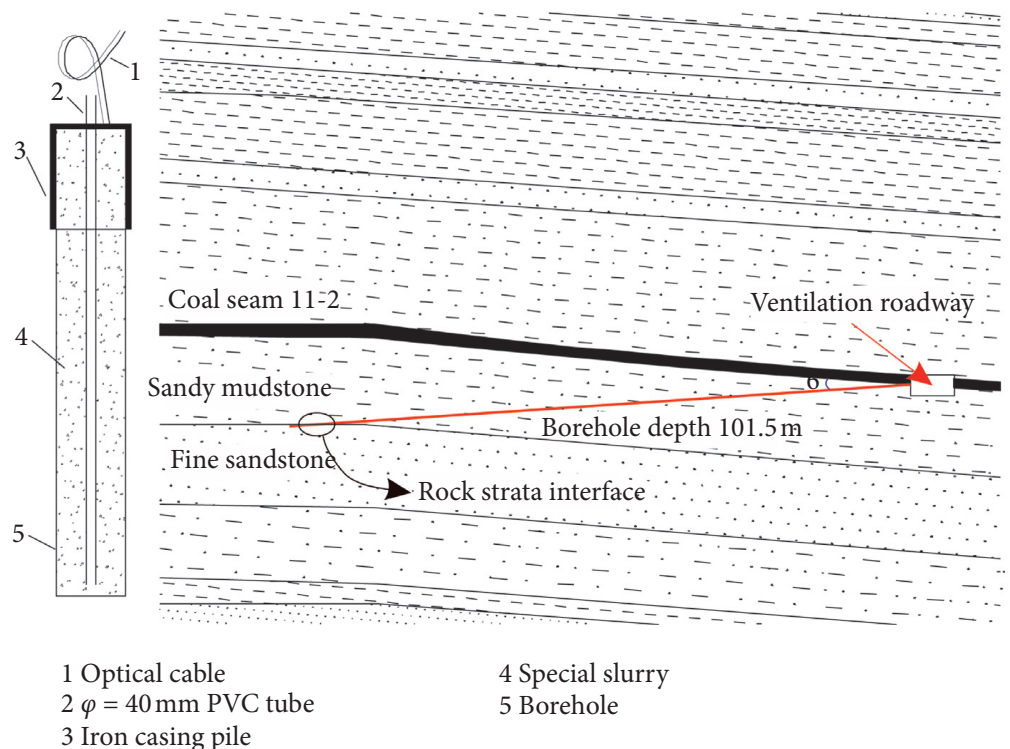

Figure 1: Installation and arrangement of the optical fiber test system.

2.3. Test Basis and Principle of Test Method. When the original stress condition of the coal and rock pillar area changes due to a mining action, the coal seam and rock strata will be deformed or destroyed. The strain parameters of the coal seam and rock strata can be tested by DFOS technology with high sensitivity. During the field test, the optical cables were embedded into the coal seam and rock strata through a borehole, which was used for real-time, continuous, full-line-length monitoring. The optical cables were processed to satisfy the requirements of large deformation monitoring. The diameter was $5 \mathrm{~mm}$, the maximum loss was only $0.3 \mathrm{~dB} / \mathrm{km}$, and the maximal tensile strength was $2000 \mathrm{~N}$. During coal mining, the stress change and disturbance of the mining space will cause continuous changes in shape, structure, and other macro features of the rock strata. A direct visual expression of rock shape change is provided by the displacement appearance. The displacement amount at each point in the surrounding rock objectively reflects the loose area of the rock mass and stability state of the surrounding rock. In the field test, the axial strain $\varepsilon$ of the optical cables varies with the external force, and the Brillouin frequency shift $v_{B}$ changes accordingly [9].

The relation between the Brillouin frequency shift and the strain and temperature is as follows:

$$
v_{\mathrm{B}}(\varepsilon, T)=v_{\mathrm{B}}(0)+\frac{\partial v_{\mathrm{B}}(\varepsilon)}{\partial \varepsilon} \varepsilon+\frac{\partial v_{\mathrm{B}}(T)}{\partial T} T,
$$

where $\partial v_{\mathrm{B}}(\varepsilon) / \partial \varepsilon$ and $\partial v_{\mathrm{B}}(T) / \partial T$ are the Brillouin frequency shift strain coefficient and Brillouin frequency shift temperature coefficient, respectively.

The experimental results show that the effect of temperature changes on the Brillouin frequency shift is negligible when the variation in temperature is less than $5^{\circ} \mathrm{C}[15]$. According to the actual monitoring data of the downhole temperature, the change in rock mass temperature in this working face is less than $3^{\circ} \mathrm{C}$. Therefore, temperature changes can be ignored, and Formula (1) can be rewritten as

$$
v_{\mathrm{B}}(\varepsilon)=v_{\mathrm{B}}(0)+\frac{\partial v_{\mathrm{B}}(\varepsilon)}{\partial \varepsilon} \varepsilon
$$

The change in the Brillouin frequency shift along the optical fiber is captured by the instrument. The strain 
value of the target in the entire detection area can be estimated from Formula (2). Simultaneously, to accurately determine the location of the anomalous area, Formula (3) was used:

$$
L=\frac{c t}{(2 n)}
$$

where $c$ is the velocity of light propagation in a vacuum, $t$ is the two-way travel time of pulsed light from transmitting to receiving for scattered light, and $n$ is the refractive index of the fiber core.

In practical engineering applications, the strain of each point in the optical cables can be determined by Formulas (2) and (3), and the strain distribution of each layer in a certain area under the floor of the protective coal and pillar is obtained. The change in strain of the floor rock strata is determined by evaluating the strain in time and space.

\section{Data Acquisition and Analysis}

3.1. Field Data Acquisition. An AV6419 optical fiber strain distribution tester (independently developed by the FortyFirst Research Institute of China Electronics Technology Group) was used for data acquisition. BOTDR can perform single-ended emission, does not need to form a closed loop, and is suitable for long-distance downhole measurements. The obtained distributed measurement dataset is large and effectively avoids the problem of point-type discontinuous measurements.

When the borehole sealing material was consolidated (generally requiring more than $10 \mathrm{~h}$ ), data acquisition was performed. At this time, the position of the working face was $140 \mathrm{~m}$ from the monitoring borehole, and the coal and rock mass in the control range of the optical cables were not affected by mining. The initial strain distribution of the sensing cable provided a basis for later comparison of monitoring data. To capture the dynamic data of the coal seam during the process, downhole continuous monitoring was performed when the working face was approximately $100 \mathrm{~m}$ from the borehole. Data acquisition was finished after the working face advanced $7 \mathrm{~m}$ above the location of the monitoring point, and 16 groups of effective test data were obtained. The strain parameters produced by the deformation of coal and rock strata obviously varied, and the data quality was good, so they provide a basis for subsequent analysis and comparison. The spatiotemporal relationship between the working face and the monitored borehole is shown in Figure 2.

3.2. Analysis of the Strain Characteristic. The monitoring borehole is located at the bottom of the protective coal pillar floor and nearly horizontal. Real-time monitoring of the strain variation characteristics and the spatiotemporal evolution of protective coal and rock pillars in the horizontal direction during the mining process can be performed using borehole sensing optical cables. Eight typical sets of data were selected for analysis, and the corresponding relationship between the strain distribution of the optical cables in the borehole and the rock strata is shown in Figure 3. The rock strata over which the borehole nearly horizontally strides over are relatively simple, and they mainly consist of sandy mudstone and fine sandstone. As shown in Figure 3, the overall strain of the sensing optical cables is tensile strain (the tensile strain is defined as positive, and the compressive strain is negative). However, there is a difference in tensile degree of the optical cables at different depths. The borehole cable with a depth greater than $95 \mathrm{~m}$ is located in fine sandstone with a strain below $320 \mu \varepsilon$. The strain value of the sensing optical cables in the range of $95-101.5 \mathrm{~m}$ is larger than that of the shallow sandy mudstone because it is located near the interface of soft and hard rock. According to the study, under the effect of mining, the deformation of the rock strata near the interface of soft and hard rock strata is greater than that of the rock strata with a small elastic modulus [15, 17]. The maximum tensile strain appears at a borehole depth of $38 \mathrm{~m}$ and is approximately $1800 \mu \varepsilon$. In addition, extreme values of tensile strain appear at $15 \mathrm{~m}$ and $28 \mathrm{~m}$, which indicates that the deformation of the rock mass in the sandy mudstone along the borehole direction is uneven. Within the borehole depth range of $0-8 \mathrm{~m}$, the strain of the tunnel is also largely effected by roadway convergence and mining effects, and the maximum value is $1400 \mu \varepsilon$. When the working face continues to approach the monitoring borehole, the outer surrounding rock is affected by the mining action, and the tensile strain of the sensing optical cables increases by various degrees; however, the deformation layer is relatively fixed.

Figure 4 shows the strain time history curve of the borehole optical cables, which take the orifice as a coordinate origin; the $X$-axis represents the depth of the borehole, the $Y$-axis represents the monitoring progress along the mining working face from inside to outside, and the $Z$-axis represents the strain of the optical cables. The figure reflects the spatiotemporal distribution of strain at different points with time. As shown in Figure 4, when the working face moves closer to the borehole, the strain of the sensing optical cables gradually increases in the range of 0-38 $\mathrm{m}$ inside the borehole, and the maximum deformation is located at a hole depth of $38 \mathrm{~m}$. The strain of the optical cables significantly increases when the working face is $18 \mathrm{~m}$ from the monitoring borehole (the monitoring date is 03-31), which indicates that the influence of mining on the surrounding rock of the working face obviously increases. The distance of $18 \mathrm{~m}$ between the working face and the borehole can be the dividing line of the strain increase rate, i.e., when the distance is more than $18 \mathrm{~m}$, the increase rate of strain at a depth of $38 \mathrm{~m}$ is $k 1$; otherwise, it is $k 2$. $k 2$ is far greater than $k 1$, indicating that the advance abutment pressure in the working face should be $18 \mathrm{~m}$. According to the analysis of the lithologic characteristics of the coal rock mass exposed by drilling holes, the influence range into the outside surrounding rock is approximately $38 \mathrm{~m}$; outside $38 \mathrm{~m}$, coal and rock strata are hardly affected by stope actions. 


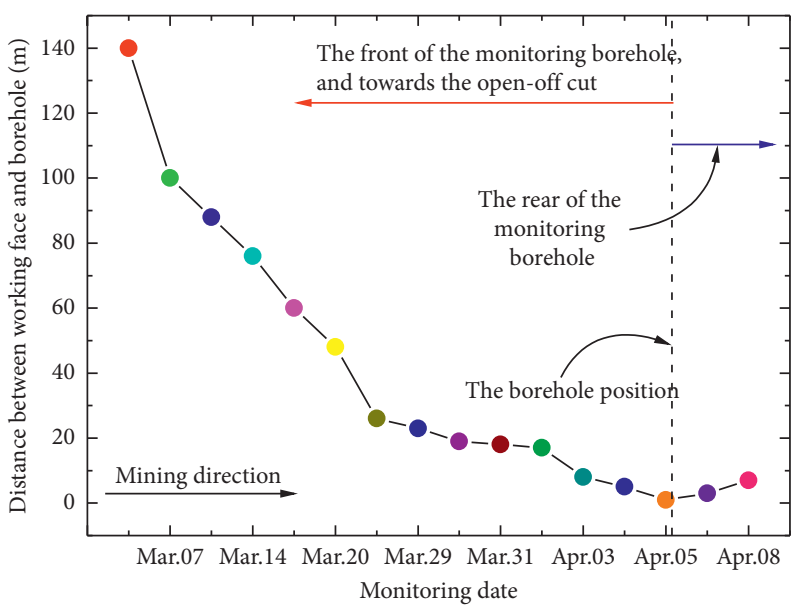

FIGURE 2: Spatiotemporal relationship between working face and monitoring borehole.

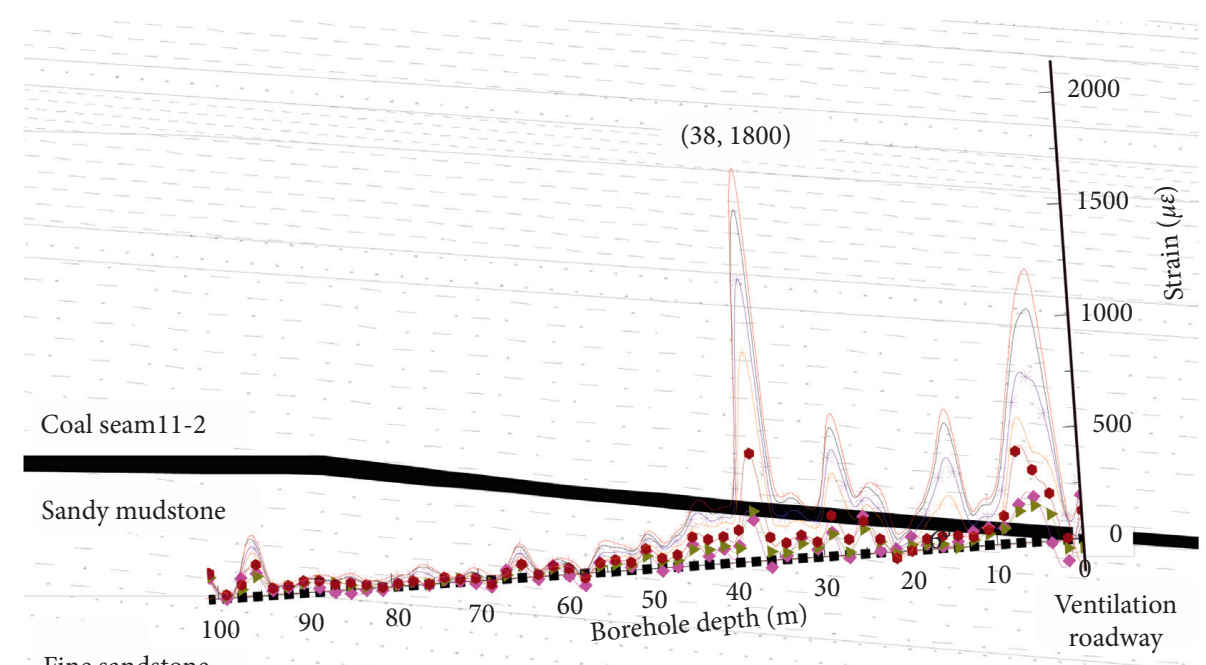

Fine sandstone

Distance between working face and borehole

$\begin{array}{llll}\rightarrow-140 \mathrm{~m} & \longrightarrow 8 \mathrm{~m} & \rightarrow-60 \mathrm{~m} & \rightarrow 1 \mathrm{~m} \\ \leftarrow-48 \mathrm{~m} & --3 \mathrm{~m} & \rightarrow-23 \mathrm{~m} & \rightarrow-7 \mathrm{~m}\end{array}$

Figure 3: Relationship between the strain distribution of sensing optical cables and formation.

3.3. Analysis of Deformation Characteristics along the Borehole Axial Direction. According to the previous assumption, after grouting in the borehole, the optical cables and rock strata are fully coupled, and there is no slippage between them; thus, they can be considered an entity. Furthermore, the axial displacement of the optical cables and the displacement of the surrounding rock can be considered as equal before the relative slippage occurred between optical cables and rock strata. The optical cables inside the borehole were in a tensile strain state, as shown in Figure 3.
As shown in Figure 5, when this assumption is true, the average axial strain and axial stress of the optical cables (rock strata) can be expressed as

$$
\begin{aligned}
\varepsilon(x) & =\frac{\mathrm{d} u(x)}{\mathrm{d} x}, \\
F(x) & =E A \varepsilon(x)=E \pi r^{2} \frac{\mathrm{d} u(x)}{\mathrm{d} x},
\end{aligned}
$$




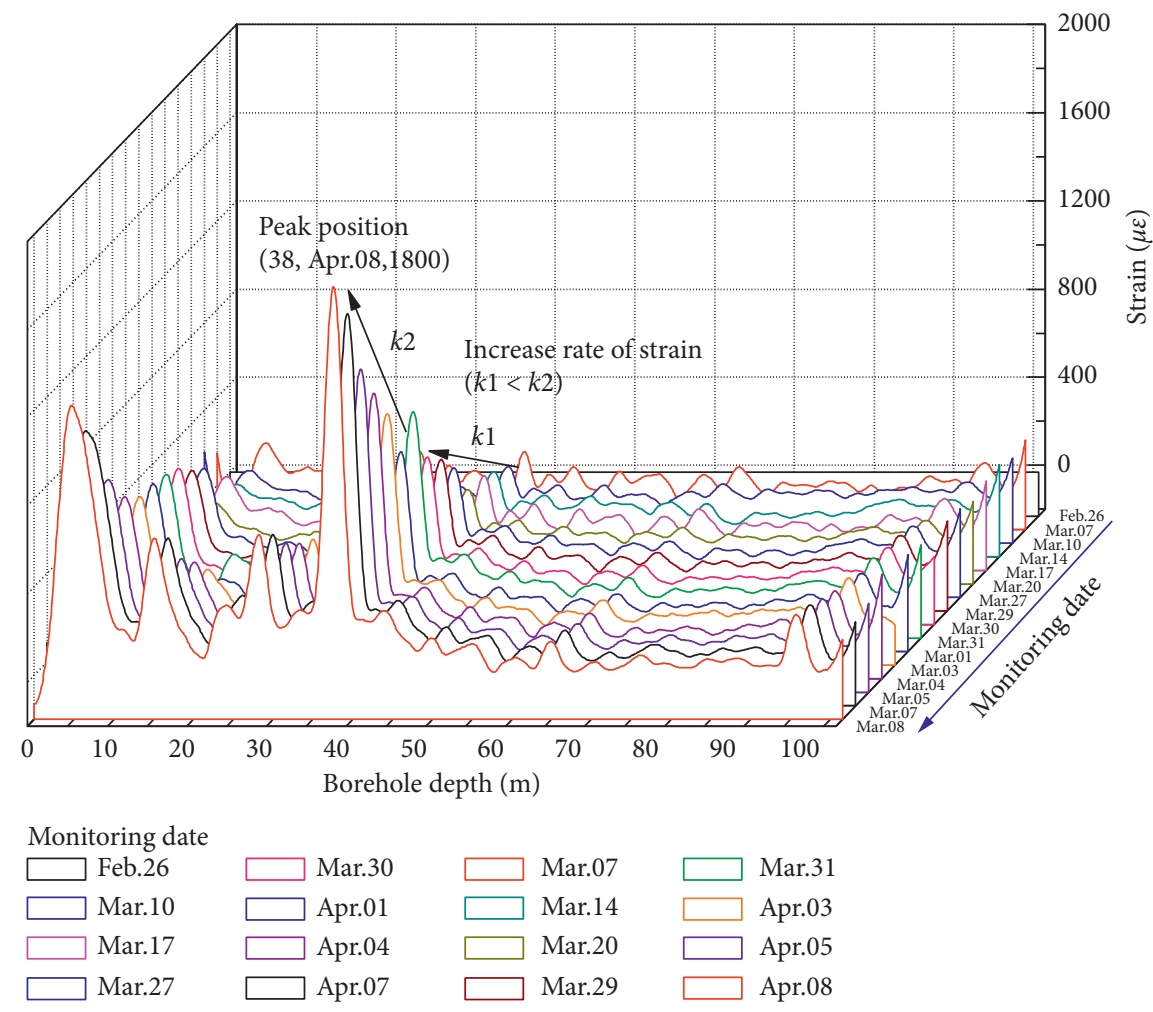

FIGURE 4: Spatiotemporal evolution diagram of the strain of optical cables in the working face.
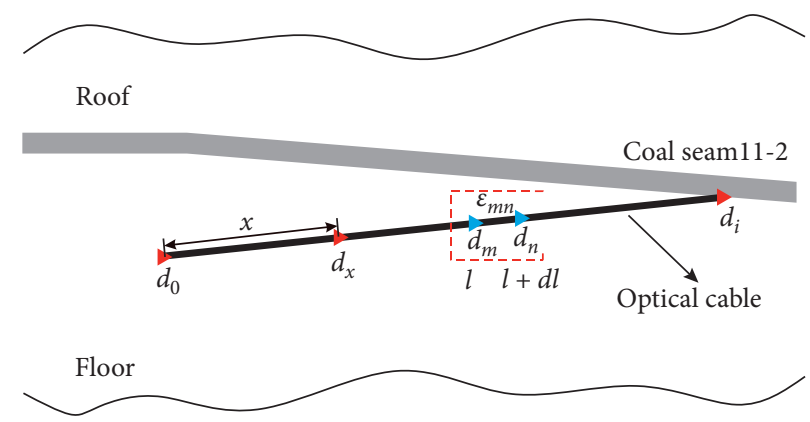

FIGURE 5: Calculation model of axial deformation along the optical cables.

where $u(x)$ is the displacement along the axial direction of the optical cables at a point $x$ from the borehole bottom, $r$ is the optical cables radius, and $E$ is the average elastic modulus of the rock strata.

To obtain the axial displacement of the optical cables, we select a microelement along the axial direction of the optical cables in the calculation model for displacement analysis; then, the displacement of the microsegment is expressed by Formula (5):

$$
\Delta l=d_{m}-d_{n}=\varepsilon_{m n} \cdot \mathrm{d} l,
$$

where $\Delta l$ is the displacement of the microelement segment; $\varepsilon_{m n}$ is the microelement segment strain; and dlis the length of an infinitesimal segment.
By considering the borehole bottom as a fixed point, the displacement expression of the optical cables is

$$
u(x)=\int_{d_{0}}^{d_{i}} \varepsilon(x) \mathrm{d} x,
$$

where $d_{0}$ is the position of borehole bottom, $0 \mathrm{~m}$; and $d_{i}$ is the position of orifice, $101.5 \mathrm{~m}$.

By integrating Formula (6), the displacement distribution diagram of rock strata in the axial direction along the borehole was obtained, as shown in Figure 6. According to the displacement characterization of the rock strata, from the bottom of the borehole to a borehole depth of $40 \mathrm{~m}$, the displacement of the rock strata is small, and the growth rate is slow; furthermore, the borehole depth from 40 to $60 \mathrm{~m}$ presents an accelerating trend. However, at a borehole depth 


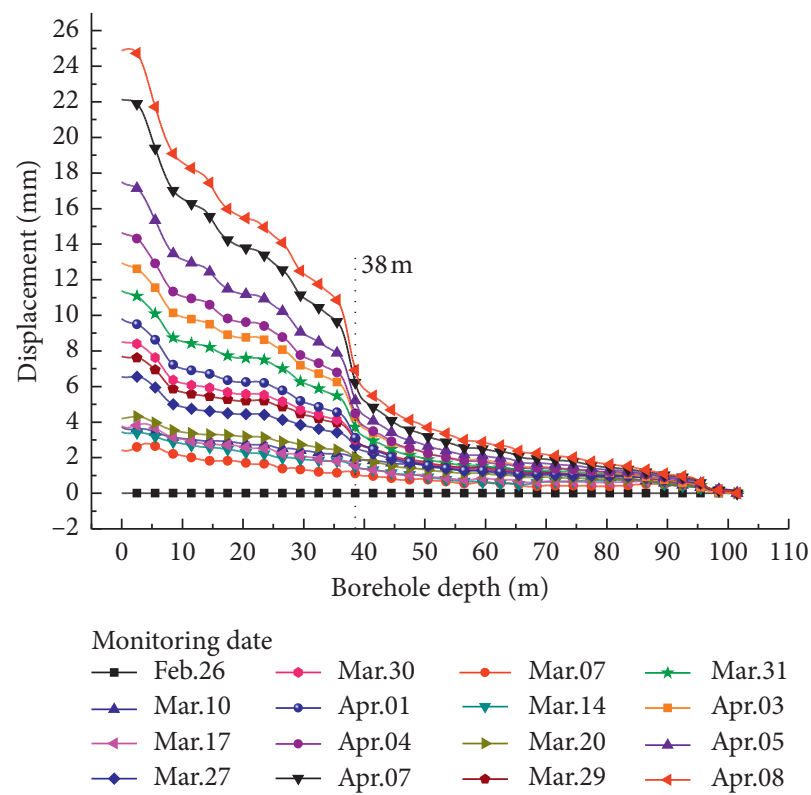

Figure 6: Distribution curve of displacement along the borehole axial direction.

of $38 \mathrm{~m}$, the displacement growth rate sharply accelerated, which indicates that the deformation of the rock strata was greatly affected by mining, which is consistent with the above analysis. When the working face advanced to $7 \mathrm{~m}$ behind the monitoring borehole, the accumulated deformation of the rock strata, i.e., the displacement, was $24.87 \mathrm{~mm}$, mainly due to the effect of coal seam mining, which caused the convergence and deformation of the surrounding rocks near the roadway and the migration of the rock strata.

\section{Numerical Simulation Analysis}

4.1. Model Construction. To further explain the effect of mining on the surrounding rock on both sides of the working face, the FLAC ${ }^{3 \mathrm{D}}$ numerical simulation software was used to analyze the stress characteristics and laws of the surrounding rock during mining. According to the mining conditions and parameters of the working face, the dimensions of the three-dimensional model are $500 \times 360 \times 180 \mathrm{~m}(x \times y \times z)$. The simulated coal seam thickness is $3 \mathrm{~m}$, and there is $10 \mathrm{~m}$ thick siltstone, $15 \mathrm{~m}$ thick fine sandstone, and other floor rock strata from the coal seam floor to the upper strata. Above the coal overburden, in consecutive order, there is $15 \mathrm{~m}$ thick sandy mudstone, $5 \mathrm{~m}$ thick fine sandstone, and other overburden. Combined with the coal and rock formation in the test area, rock in the $x$ direction from 0 to $60 \mathrm{~m}$ is horizontal, and rock outside $60 \mathrm{~m}$ tilts downward at a dip angle of $6^{\circ}$. The simulation plane is $240 \mathrm{~m}$ long, and the open-off cut position is $x=160-400 \mathrm{~m}$ and $y=100 \mathrm{~m}$. The coal seam is mined along the strike direction, and the excavation interval is $20 \mathrm{~m}$. The total excavation is $160 \mathrm{~m}$ long.

Based on the grid division of different rock strata in the model, the $x$ and $z$ directions are encrypted in the research focus area (optical cables monitoring area) (Figure 7). The $x$ - direction width of the encryption area is $1 \mathrm{~m}$. Twenty-five vertical stress monitoring points are arranged in the lower left bottom floor of the working face at $y=260 \mathrm{~m}$ (the angle of depression is approximately $6^{\circ}$ ), and the nearest and farthest monitoring points from the lower left side of the working face are $4 \mathrm{~m}$ and $100 \mathrm{~m}$, respectively. The model has 34162 compute nodes and 30744 grids in total. The boundary conditions of the model are as follows: the front, rear, left, and right boundaries are fixed zero-displacement boundaries with the bottom surface, and a vertical load of $14 \mathrm{MPa}$ is applied to simulate an approximately $750 \mathrm{~m}$ thick rock (soil) layer.

4.2. Simulation Result. According to the test data of the physical and mechanical properties of indoor rock samples and considering the size effect of the rock mass, the laboratory-obtained strength parameters of rock blocks were reduced by $1 / 4$ [24]. The selected values of the lithologic parameters in the numerical model were obtained. Figure 8 is the distribution map of the plastic zone of the surrounding rock when the excavation distance is $100-160 \mathrm{~m}$. The failure height (depth) and the damage scope of the roof and floor of the goaf increase with the increase in mining scope of the working face. Simultaneously, the disturbance range on both sides of the goaf caused by the excavation of the coal seam increases. The maximum lateral disturbance of the roof increases from $33 \mathrm{~m}$ to $40 \mathrm{~m}$ when the working face advances to $100 \mathrm{~m}$ and ends at $160 \mathrm{~m}$, while the lateral disturbance range of the floor is slightly smaller than that of the roof at $30-36 \mathrm{~m}$. When the working face advances to $140 \mathrm{~m}$, the lateral disturbance range of the roof or floor tends to be stable. The numerical analysis result is similar to that in the field measured by the optical fiber on the outside floor of the working face. 


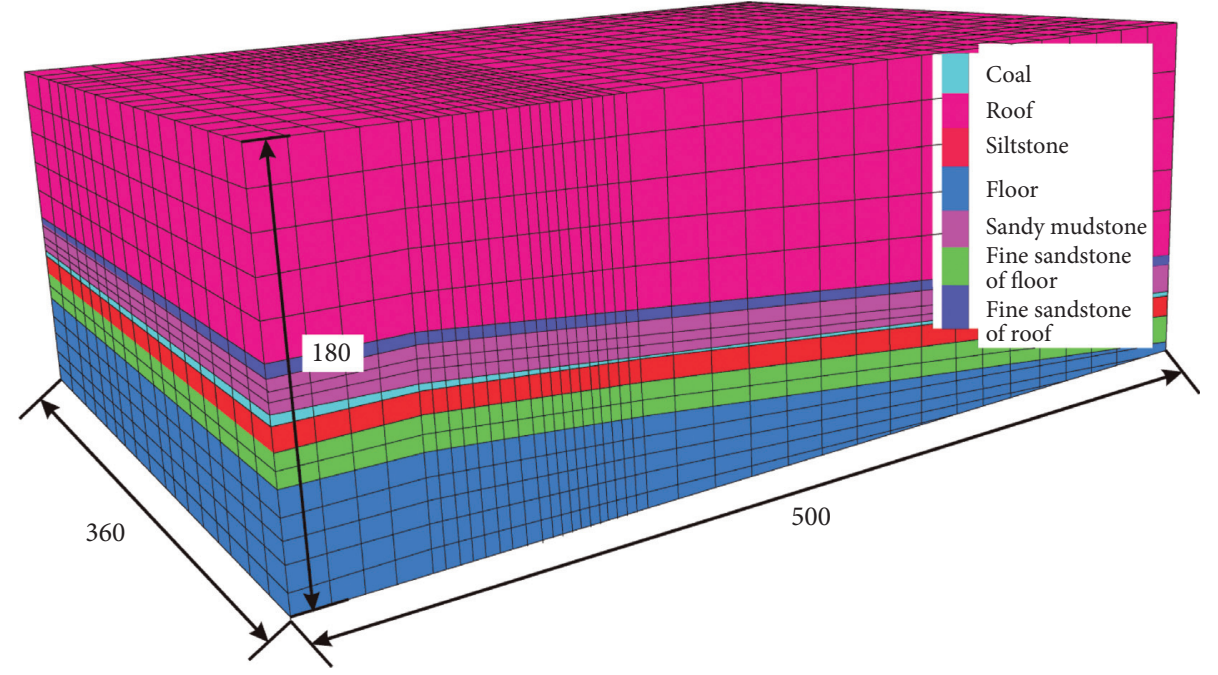

Figure 7: Model unit division and model size.
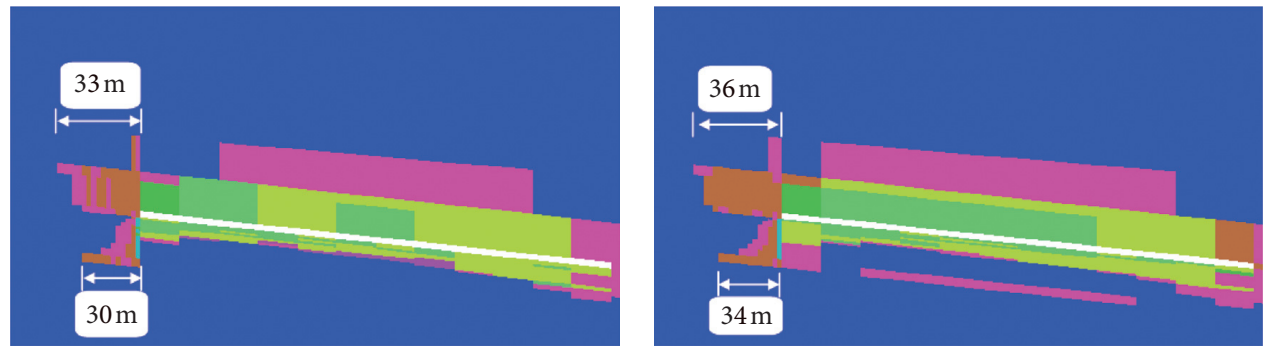

None
Shear(n)-shear $(\mathrm{p})$
Shear(n)-shear(p)-tension $(\mathrm{p})$
Shear(n)-tension(p)-shear(p)-ten
Shear(p)
Shear(p)-tension $(\mathrm{p})$
Tension $(\mathrm{p})$-shear $(\mathrm{p})$-tension $(\mathrm{p})$
Tension $(\mathrm{p})$

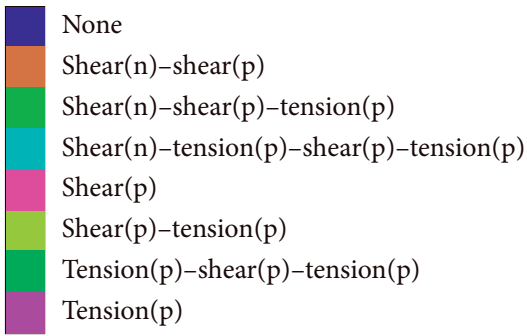

(a)
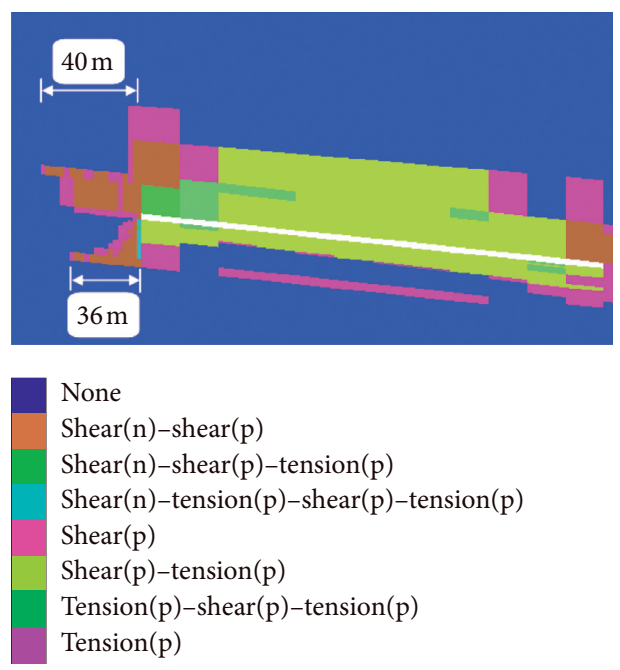

(c)

FIGURE 8: Distribution of plastic zone of surrounding rock at different advancing distance of working face. (a) Advancing $100 \mathrm{~m}$, (b) advancing $140 \mathrm{~m}$, and (c) advancing $160 \mathrm{~m}$. 


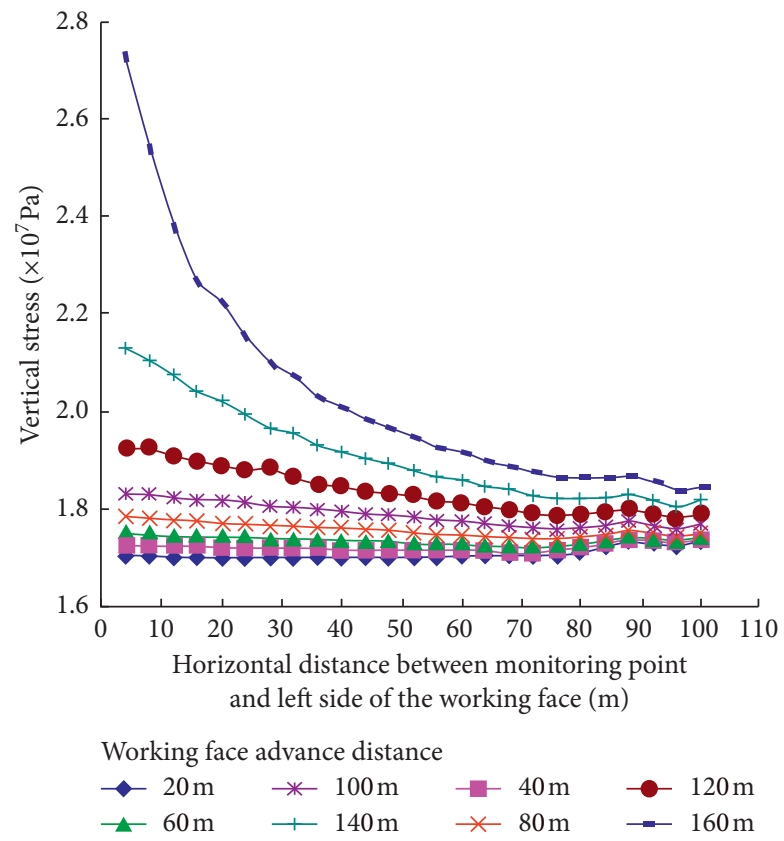

FIGURE 9: Vertical stress variation of each monitoring point at different advance distance of the working face.

The vertical stress change at each monitoring point and different advancing distances of the working face in the numerical simulation is shown in Figure 9. Figure 8 shows that before the working face has advanced to $140 \mathrm{~m}$, the vertical stress of each monitoring point does not greatly change because the monitoring section is far from the working face, and the effect of mining on the side is small. When the working face has advanced to $140 \mathrm{~m}$ and $160 \mathrm{~m}$ (exposing the monitoring section), the effect of the abutment pressure is approximately 30-40 $\mathrm{m}$ (Figure 8); however, outside $40 \mathrm{~m}$, the vertical stress at each monitoring point gradually tends toward the original rock stress. This finding is consistent with the results of the previous optical cables test analysis.

\section{Conclusions and Discussion}

In this paper, the DFOS technology was used to measure the deformation characteristics of the coal and rock pillar area in working face 1231(1) of the stope. The stress characteristics and deformation laws of the rock strata were systematically analyzed in the coal seam mining process, and relevant parameters were verified by numerical simulation results. The following conclusions are obtained, and suggestions are made for the follow-up study:

(1) Combined with the stope process of the working face, the DFOS technology in the borehole was used to dynamically monitor the rock strata strain parameters in the protective coal pillar area. The results of the FLAC ${ }^{3 \mathrm{D}}$ numerical simulation were combined for a comprehensive analysis to reveal the disturbance effect of coal mining on the protective coal pillar.
(2) Under the mining conditions, the outer protective coal pillar area of the working face is affected by the tensile strain along the borehole direction; the maximum strain is $1800 \mu \varepsilon$, the rock strata disturbance range (i.e., the reserved width of the protective coal and rock pillar) is $38 \mathrm{~m}$, and the maximum displacement of the rock strata is $24.87 \mathrm{~mm}$.

(3) Combined with numerical simulation, the characteristics of the stress and deformation of coal and rock pillars in the working face were comprehensively analyzed. At approximately $38 \mathrm{~m}$ outside the working face, both measured displacement and simulated stress steeply increase. The results of the two methods are consistent with each other.

(4) Affected by the field borehole construction, the coal pillar has not been fully revealed by underground field test borehole, and special research on coal seams with different thicknesses should be performed in the following study to improve the pertinence of the test analysis. Simultaneously, a test contrast experiment with the traditional stress test device, and the stress condition analysis and assessment should be performed according to the optical cables test data to improve the comprehensive utilization efficiency of the data.

In conclusion, this study shows that the DFOS technology can be applied in boreholes to test the mechanical parameters of the mine rock mass. At present, the mining of deep coal resources has the complicated mechanical problem of "three high and one disturbance," which causes frequent occurrences of dynamic disasters in deep coal mines and seriously affects mining safety. Thus, monitoring the spatiotemporal law of the surrounding rock strata stress 
distribution using DFOS technology in the borehole will be a popular method in the future.

\section{Data Availability}

The nature of the data is the field observation data, numerical simulation data, and the theoretical calculation data. The data used to support the findings of this study are available from the corresponding author upon request.

\section{Conflicts of Interest}

The authors declare that there are no conflicts of interest regarding the publication of this paper.

\section{Acknowledgments}

The authors gratefully acknowledge the financial support of the Key Research and Development Plan Projects of Anhui Province (grant no. 1804a0808213), the National Natural Science Foundation of China (grant no. 41877268), the Major Project of Natural Science Research in Colleges and Universities of Anhui Province (grant no. KJ2016SD17), and Academic and Technological Leader Project of Anhui Province (grant no. gxbjZD2016048).

\section{References}

[1] F. Y. Wei, J. J. Chen, and Y. F. Zou, "Probing into influence factors and changing laws of coal pillar for protection buildings," China Mining Magazine, vol. 15, no. 12, pp. 61-63, 2006.

[2] G. H. Zhi and B. Zheng, "Protective coal pillar set method and development tendency in China," Coal Engineering, vol. 6, pp. 9-11, 2009.

[3] M. C. He, H. P. Xie, S. P. Peng, and Y. D. Jiang, "Study on rock mechanics in deep mining engineering," Chinese Journal of Rock Mechanics and Engineering, vol. 24, no. 16, pp. 28032813, 2005.

[4] J. H. Han, J. Q. Zou, C. C. Hu, and W. H. Yang, "Study on size design of shaft protection rock/coal pillars in thick soil and thin rock strata," Energies, vol. 12, no. 13, 2553 pages, 2019.

[5] X. L. Lu, C. A. You, F. Sun, and Y. B. Zhan, "Numerical simulation of rational protective pillar of fault," Rock and Soil Mechanics, vol. 27, no. 1, pp. 239-242, 2006.

[6] F. Y. Wei, J. J. Chen, and Y. F. Zou, "Analytical model of protective coal pillar design for vertical section method," Journal of China Coal Society, vol. 33, no. 3, pp. 256-258, 2008.

[7] X. Y. Zhang, J. C. Chang, and L. Wang, "Study on surrounding rock stress and reasonable pillar of mining induced roadway groups in deep well," Journal of Mining and Safety Engineering, vol. 27, no. 1, pp. 72-76, 2010.

[8] K. Fujihashi, H. Uehara, and M. Okustu, "Development of a road disaster monitoring system using fiber optic distributed strain sensor," NTT Technical Review, vol. 39, pp. 420-428, 2003.

[9] B. Shi, H. Z. Xu, D. Zhang et al., "Feasibility study on application of Botdr to health monitoring for large infrastructure engineering," Chinese Journal of Rock Mechanics and Engineering, vol. 23, no. 3, pp. 493-499, 2004.

[10] F. Matta, F. Bastianini, N. Galati, P. Casadei, and A. Nanni, "Distributed strain measurement in steel bridge with fiber optic sensors: validation through diagnostic load test," Journal of Performance of Constructed Facilities, vol. 22, no. 4, pp. 264-273, 2008.

[11] L. Gao, Y. H. Gong, H. L. Liu, B. Q. Ji, Y. N. Xuan, and Y. Ma, "Experiment and numerical study on deformation measurement of cast-in-place concrete large-diameter pipe pile using optical frequency domain reflectometer technology," Applied Sciences, vol. 8, no. 9, Article ID 1450, 13 pages, 2018.

[12] H. H. Zhu, B. Shi, and C. C. Zhang, "FBG-based monitoring of geohazards: current status and trends," Sensors, vol. 17, no. 3, p. 23, Article ID 452, 2017.

[13] A. Barrias, J. R. Casas, and S. Villalba, "A review of distributed optical fiber sensors for civil engineering applications," Sensors, vol. 16, no. 5, p. 35, Article ID 748, 2016.

[14] D. Zang, J. C. Wang, P. S. Zhang, and B. Shi, "Internal strain monitoring for coal mining similarity model based on distributed fiber optical sensing," Measurement, vol. 97, pp. 234-241, 2016.

[15] D. Zhang, P. S. Zhang, B. Shi, H. X. Wang, and C. S. Li, "Monitoring and analysis of overburden deformation and failure using distributed fiber optic sensing," Chinese Journal of Geotechnical Engineering, vol. 37, no. 5, pp. 952-957, 2015.

[16] J. Chai, Q. Yuan, Y. Li, D. D. Zhang, and Q. Li, "Experimental study on overlying strata deformation based on distributed optical fiber sensing," Chinese Journal of Rock Mechanics and Engineering, vol. 35, no. 2, pp. 3589-3596, 2016.

[17] B. Y. Sun, P. S. Zhang, R. X. Wu, and L. Q. Guo, "Dynamic detection and analysis of overburden deformation and failure in a mining face using distributed optical fiber sensing," Journal of Geophysics and Engineering, vol. 15, no. 6, pp. 2545-2555, 2018.

[18] T. Hu, G. Y. Hou, and Z. X. Li, "The field monitoring experiment of the roof strata movement in coal mining based on DFOS," Sensors, vol. 20, no. 5, Article ID 1318, 31 pages, 2020.

[19] B. Tang and H. Cheng, "Application of distributed optical fiber sensing technology in surrounding rock deformation control of TBM-excavated coal mine roadway," Journal of Sensors, vol. 2018, Article ID 8010746, 10 pages, 2018.

[20] G. Cheng, B. Shi, H.-H. Zhu, C.-C. Zhang, and J.-H. Wu, "A field study on distributed fiber optic deformation monitoring of overlying strata during coal mining," Journal of Civil Structural Health Monitoring, vol. 5, no. 5, pp. 553-562, 2015.

[21] Y. Liu, W. Li, J. He, S. Liu, L. Cai, and G. Cheng, "Application of Brillouin optical time domain reflectometry to dynamic monitoring of overburden deformation and failure caused by underground mining," International Journal of Rock Mechanics and Mining Sciences, vol. 106, pp. 133-143, 2018.

[22] C. C. Zhang, B. Shi, H. H. Zhu, and G. Q. Wei, "Theoretical analysis of mechanical coupling between soil and fiber optic strain sensing cable for distributed monitoring of ground settlement," Chinese Journal of Geotechnical Engineering, vol. 41, no. 9, pp. 1670-1678, 2019.

[23] J. Chai, Y. B. Ouyang, D. D. Zhang, and W. L. Lei, "Theoretical analysis of the mechanical coupling between rock and optical fiber for distributed sensing of overlying strata deformation," Journal of Mining and Strata Control Engineering, vol. 2, no. 3, pp. 33-38, 2020.

[24] S. P. Peng and J. A. Wang, Safe Coal Mining in Confined Aquifers, p. 110, Beijing: Coal Industry Press, Beijing, China, 2001. 